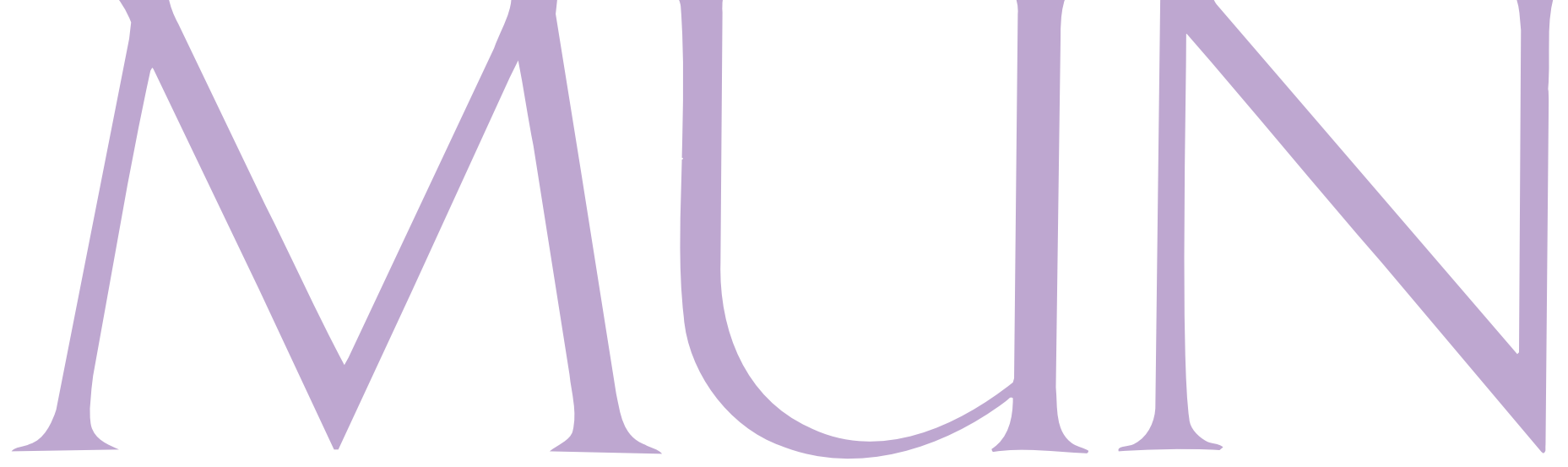

Multilinguismo

\section{9: Ano Internacional das Línguas Indígenas}

Estima-se que existam de seis a sete mil línguas no mundo. Entretanto, 97\% da população mundial fala apenas 4\% dessas línguas. De acordo com previsões mais otimistas, até 2100 , só restarão $50 \%$ desses idiomas. Para os mais pessimistas, no entanto, existirão somente $10 \%$, ou seja, cerca de 600 a 700 línguas, conforme aponta o vice-presidente do Conselho Intergovernamental do Programa de Informação para Todos da Unesco (Ifap), Evgeny Kuzmin, que também é presidente do Grupo de Trabalho Unesco/Ifap sobre multilinguismo.

Com abertura realizada em Paris, em 28 de janeiro de 2019, o Ano Internacional das Línguas Indígenas (2019IYIL) é uma campanha promovida pela Unesco, em nível mundial, para a sensibilização contra as ameaças que pairam sobre as línguas indígenas e as suas comunidades linguísticas. "A ação visa mobilizar instituições, comunidades e pessoas ao redor do globo para entender melhor a questão da perda linguística e cultural, desenvolver estratégias de reversão e garantir que as línguas estejam aqui no futuro",

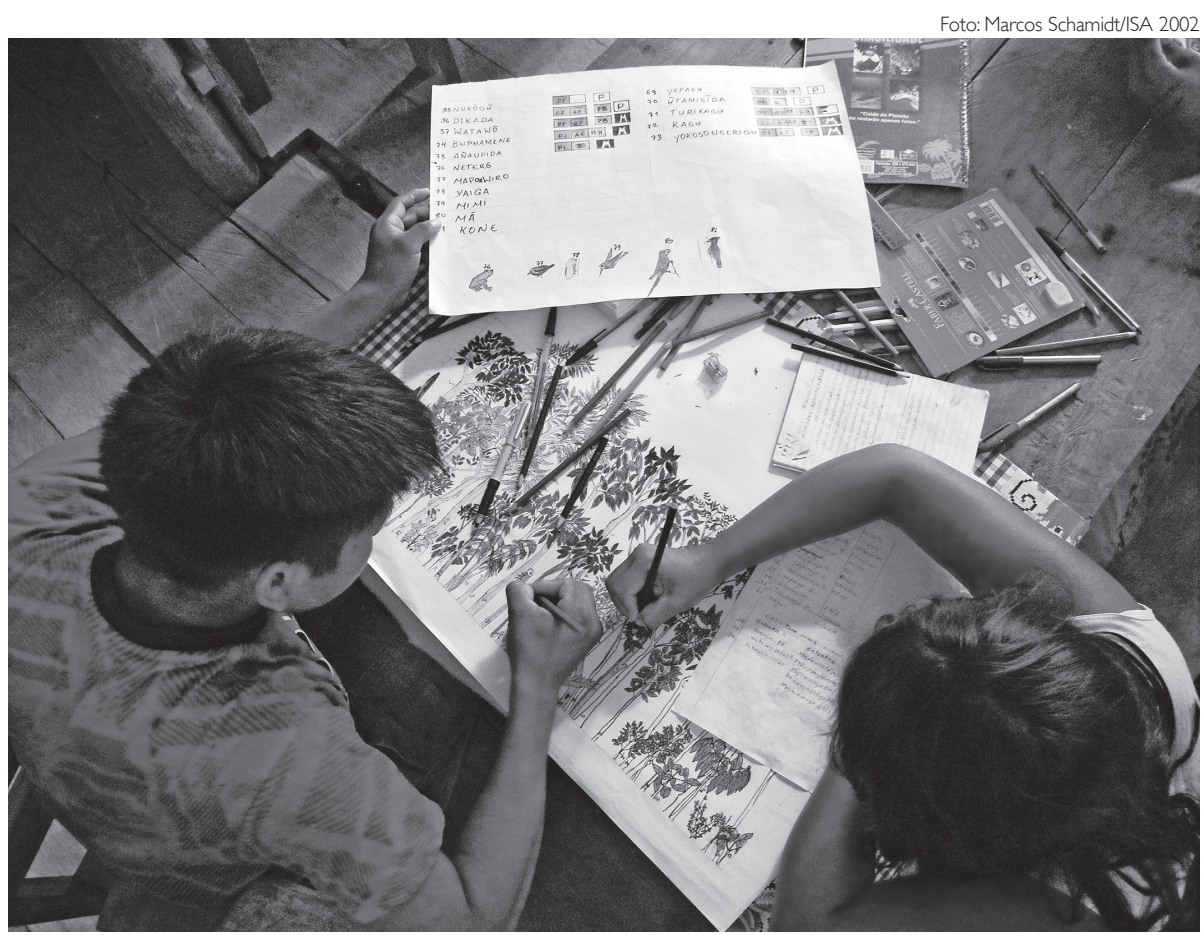

Alunos dos ensino médio da escola Tuyuka desenhando paisagens, comunidade S.Pedro

\section{LÍNGUAS EM PERIGO}

A escolha de 2019 como Ano Internacional das Línguas Indígenas foi proposta pelo Fórum Permanente das Nações Unidas para os Assuntos Indígenas (UNPFII ou PFII), órgão criado em 2000 como fruto de discussões da Conferência Mundial sobre os Direitos Humanos de 1993, ocorrida em Viena. "Podemos dizer que as Nações Unidas, através da Unesco, têm uma preocupação permanente sobre o assunto", diz Oliveira.

A política de fomento e estímulo ao multilinguismo foi iniciada em 1993 com o lançamento do Programa Unesco para as Línguas em Perigo. Em 1996, é lançada a primeira edição do Atlas das Línguas em Perigo. Em 1999 é instituído o Dia Internacional das Línguas Maternas: 21 de fevereiro. 0 Ano Internacional das Línguas, extensivo a todas as sete mil comunidades linguísticas do mundo, foi criado em 2008. 


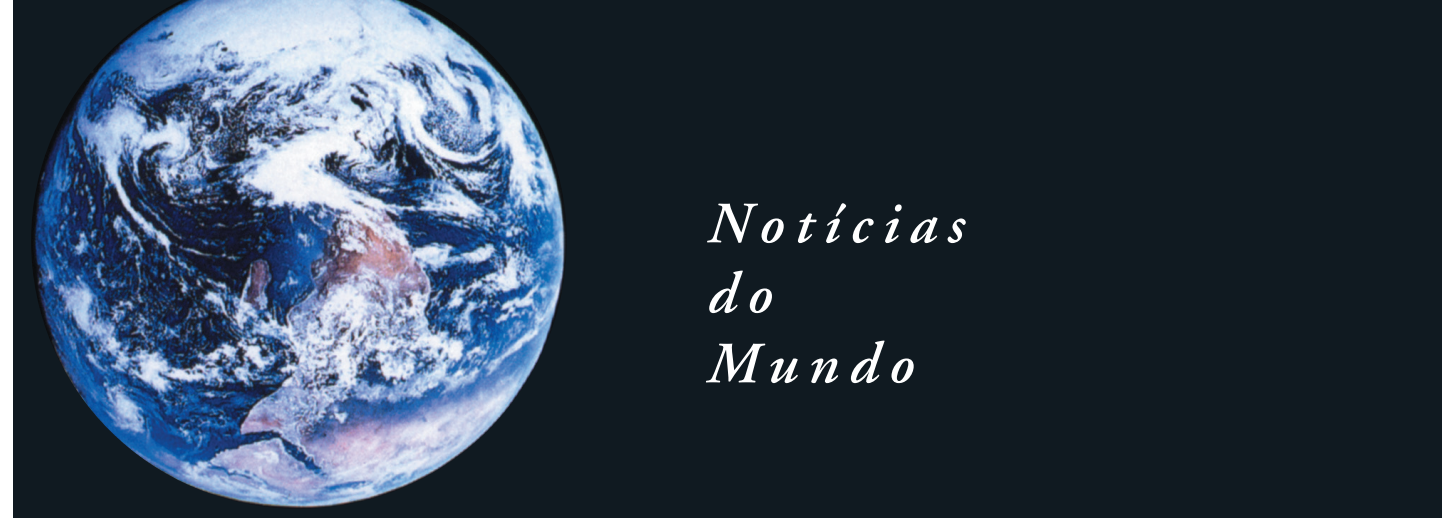

explica o coordenador da Cátedra Unesco sobre Políticas Linguísticas para o Multilinguismo, Gilvan Müller de Oliveira, da Universidade Federal de Santa Catarina (UFSC). Centenas de ações estão previstas ao redor do mundo. Em 21 e 22 de fevereiro, foi realizada a I Conferência Internacional sobre as Línguas Indígenas da Índia, na Universidade de Hyderabab. Estão previstas três conferências de Estado, 17 reunióes internacionais, 15 congressos internacionais, 20 seminários e cursos de formação, 14 simpósios, entre outros, além da participação permanente de 11 ONGs.

CULTURAS VULNERÁVEIS A cada quinze dias, uma língua morre. As mais ameaçadas de desaparecimento são as línguas indígenas, cujos povos são os mais vulneráveis. Segundo Kuzmin, essa situação pode resultar em uma séria redução da diversidade cultural e intelectual, que sempre foi a base da vida humana em nosso planeta. "A extinção de línguas minoritárias significa a extinção de conhecimentos vastos e essenciais nelas embutidos, especialmente o conhecimento da natureza, do clima, doenças e perspectivas dos povos que vivem, por exemplo, no extremo norte do planeta, nas regiões pouco acessíveis das selvas africanas, ou nas áreas de alta montanha, isto é, nos territórios que estão agora no centro das atenções de grandes empresas e políticos. Por isso, é indiscutível que as línguas minoritárias devam ser cuidadas, por mais difícil e dispendiosa que seja essa tarefa", afirma Kuzmin.

A globalização, a internacionalização da economia, projetos de desenvolvimento, migrações e advento do ciberespaço são elencados como causas da extinção das línguas. "Estes desenvolvimentos, em geral feitos na velocidade voraz do capitalismo, trouxeram deslocamentos culturais e territoriais inéditos na história sem dar às comunidades linguísticas tempo para uma atualização estratégica de suas visões de mundo, o uso de seus conhecimentos e suas linguagens", aponta Oliveira.

A perda pode ser de "âmbito" ou ser uma "descontinuidade intergeracional". No primeiro caso, há diminuição paulatina dos espaços em que uma língua é usada. Na Índia, por exemplo, o telugu, embora tenha 86 milhôes de falantes (mais que o italiano, por exemplo), está cada vez menos presente nas escolas, dado o avanço das "english-medium schools" no país. No segundo caso, há diminuição da transmissão, quando os filhos já não falam ou não querem falar a língua da família ou dos pais. "Quase sempre estas perdas estão inter-relacionadas", diz Oliveira. A Unesco, em seu Atlas das
Linguas em Perigo (ver box), considera cinco principais graus para definição da vitalidade das línguas: vulneráveis, definitivamente ameaçadas, severamente ameaçadas, criticamente ameaçadas e extintas. Em uma sexta categoria entrariam as revitalizadas, muito poucas. "Em geral uma língua entra num processo de perda quando mudam as condições de vida de uma comunidade e quando uma língua mais poderosa começa a atrair os falantes, porque espelha melhor ou parece espelhar melhor as novas condições de vida”, destaca o pesquisador.

PRESERVAÇÃo Uma ação desenvolvida com a língua tuyuka, no Amazonas, é exemplo de preservação. Oliveira trabalhou com falantes desse idioma, no Alto Rio Negro, no município de São Gabriel da Cachoeira, entre 1999 e 2004. A língua estava ameaçada pelo processo de tukanização, isto é, estava sendo deslocada pela língua tukano, mais poderosa, com mais falantes na região. $\mathrm{O}$ pesquisador criou um sistema de escrita e a comunidade criou uma escola monolíngue em tuyuka, para levar as crianças a falar a língua novamente. "Quando falamos em 'preservar uma língua', não estamos falando em conservar amostragens gravadas de uma língua em um instituto de pesquisa, mas de uma mudança no compor- 


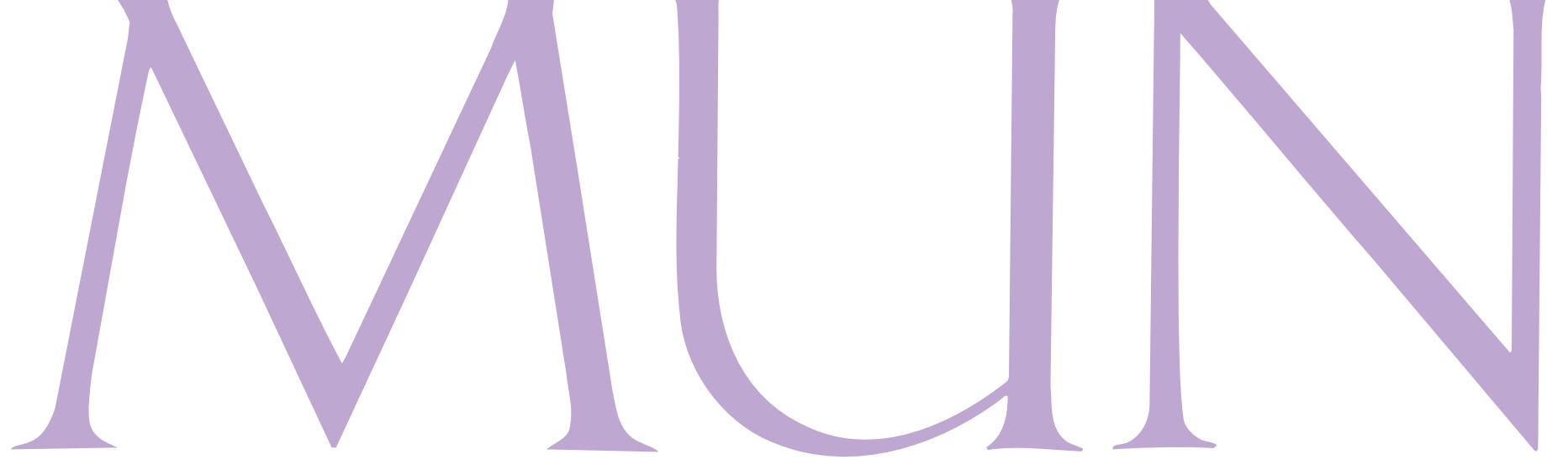

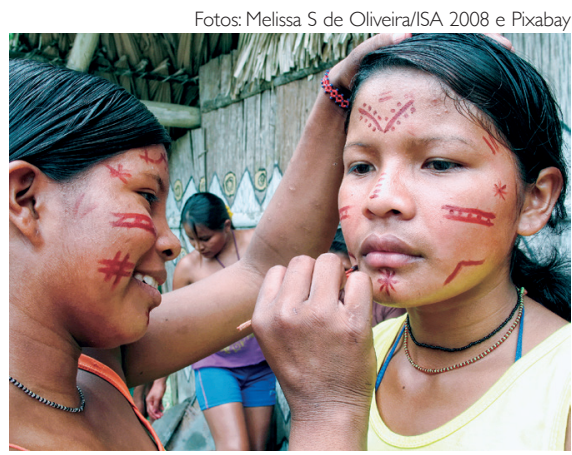

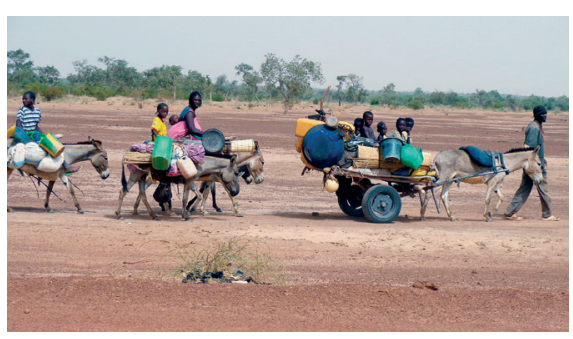

Acima, alunas Tuyuka de ensino médio, abaixo, refugiados cruzam deserto

tamento linguístico de uma comunidade, de quando ela se torna capaz de perceber a sua língua como um ativo político e econômico, e a partir daí interpreta, analisa e começa paulatinamente a modificar o seu lugar no mundo utilizando e aprimorando a sua língua para novos usos", esclarece.

Isso pode envolver educação, com ensino bi ou multilíngue, e oficialização de determinadas línguas, por exemplo. Desde 2002, 31 municípios brasileiros co-oficializaram 11 línguas: sete indígenas (tukano, baniwa, nheengatu, wapixana, macuchi, guarani e akwé-xerente) e quatro de imigração (pomerano, talian, hunsrückisch e alemão).
O PAPEL DAS TECNOLOGIAS Uma importante medida de preservação das línguas e promoção da diversidade linguística e cultural é o desenvolvimento e a implantação de tecnologias de processamento de linguagem natural, como compreensão de texto, tradução automática, reconhecimento de voz etc. São tecnologias que podem ajudar a garantir e a fortalecer a representação e o uso de línguas minoritárias nas redes. "Além de retardar o enfraquecimento e extinção dessas línguas, essas tecnologias também podem revitalizá-las, não apenas no mundo digital, mas também na vida real", acredita Evgeny Kuzmin, também presidente do comitê russo do Ifap, que incentiva os Estados membros da Unesco a incorporar a diversidade cultural e linguística na formulação e implementação de políticas e soluçôes de inovação digital e a utilizar ferramentas adequadas para promover a diversidade linguística e o multilinguismo no ciberespaço.

Conforme estimativas de Joseph Mariani, cientista da computação francês, das sete mil línguas existentes, menos de cem, ou seja, menos de $2 \%$, são equipadas com essas tecnologias de linguagem. Menos de dez são relativamente cobertas por essas tecnologias, sendo que somente a língua inglesa é bem coberta. Essa situação, que exclui $98 \%$ das línguas, amplia a marginalização e pode significar sua extinção. "A língua é o principal vetor da comunicação e a transmissão do conhecimento e seu uso em novas tecnologias determinam o grau de acesso e participação nas sociedades do conhecimento", aponta Kuzmin.

Além das línguas autóctones, para o vice-presidente do Ifap, quase todas as línguas se deparam com o risco de perder seu papel em campos como educação, ciência, mídia etc.: "Institutos de pesquisa do mundo publicam cada vez mais os resultados de seus estudos em inglês e não fornecem traduçôes para as respectivas línguas nacionais. Universidades oferecem mais e mais cursos hoje exclusivamente em inglês". Se, por um lado, o inglês permite que pessoas se comuniquem, como a repórter brasileira e o entrevistado russo, por outro lado, impõe problemas: "Se todos começarmos a pensar em inglês, talvez possamos nos tornar economistas brilhantes e gerentes mais eficazes do que somos hoje, mas como vamos viver sem os nossos conceitos nacionais, espirituais e intelectuais que não têm um análogo em inglês?", pergunta-se. "Por isso, estou convencido de que temos que refletir sobre o destino de todas as línguas do mundo e cuidar delas, embora de modos diferentes", conclui.

Mariana Garcia de Castro Alves 